\title{
Assessment of Skin Redraping after Liposuction in Treatment of Gynecomastia Grade III Simon`s Classification
}

\author{
Ahmad Emadeldeen Ali ${ }^{1, *}$ MSc., SamyAbdelsattar Eleowa ${ }^{1}$ PhD. and Mohammed Hosny Khalifa ${ }^{1}$ MD.
}

* Corresponding Author:

Ahmad Emadeldeen Ali

raaef.emad@gmail.com

Received for publication May 29,

2021; Accepted July 31, 2021;

Published online July 31, 2021.

Copyright The Authors published by Al-Azhar University, Faculty of Medicine, Cairo, Egypt. Users have the right to read, download, copy, distribute, print, search, or link to the full texts of articles under the following conditions: Creative Commons Attribution-Share Alike 4.0 International Public License (CC $B Y-S A$ 4.0).

doi: 10.21608/aimj.2021.73006.1485

${ }^{1}$ Department of Plastic Surgery and Burn, Faculty of Medicine, Al- Azhar University, Cairo, Egypt.

Disclosure: The authors have no financial interest to declare in relation to the content of this article. The Article Processing Charge was paid for by the authors.

Authorship: All authors have a substantial contribution to the article.

\begin{abstract}
Background: Gynecomastia is the most common breast disorder in men. The usual treatment of grade III is surgical excision of the excess skin which may cause embarrassment and dissatisfying results.

Objective: To evaluate skin redraping after traditional liposuction in management of grade III gynecomastia Simon`s classification.

Patients and Methods: In this study, 20 patients with grade III gynecomastia were selected with age group between 18 and 40 years old with mean $28.25 \pm 4.18,18$ patients were idiopathic while 2 patients were drug induced, 19 cases were bilateral and one case were unilateral. It was a prospective observational cohort study to assess the effectiveness traditional liposuction for correction of grade III gynecomastia with excision of the gland through a semicircular infraareolar incision when needed, 11 cases underwent surgical gland excision while 9 cases didn't need to. The study was conducted at AlAzhar university hospitals (Al-Hussien and Sayed Galal).

Results: Age group ranged from 18 to 40 with a mean on $28.25 \pm 4.18$. The subjective results for all patients at 3 months assessment point. Four patients scored very satisfied, eight stated satisfied, another four stated neither satisfied nor dissatisfied while three patients declared dissatisfaction and only one was very dissatisfied. The average sternal notch to nipple length pre and three months postoperative were respectively $27 \mathrm{~cm}$ and $22 \mathrm{~cm}$. Many factors have contributed in our success rate; the selection of young nonsmoker patient with no co morbid diseases or evidence of defective elasticity (varicosities or hernias), the adequate preparation, amount and duration of the tumescent and the proper choice of the corset size and fiber as well as wearing it for the whole time of the study ( 3 months). The semicircular periareolar incision scars are not well defined as it become camouflaged by the color change between normal skin areola.

Conclusion: Conventional liposuction alone could be a reliable method to treat grade III gynecomastia in young patient with a good skin quality and helps in avoidance of undesirable scars.
\end{abstract}

Keywords: Skin Redraping After Liposuction; Gynecomastia Grade III Simon`s Classification.

\section{INTRODUCTION}

'Gynecomastia' is considered the most common benign disorder of the breast tissue in men. At adolescence, about $70 \%$ of men are thought to display a sort of 'gynecomastia'. the skin contains $4 \%$ fat-free elastin. the long-range elastic extensibility is considered one of its main characteristics, which allows it to return to its original shape even after maximal strain. Elastin also plays an important role in the return of collagen to its wavy posture at rest. that makes elastin responsible for the skin recoil capability. The biomechanical properties of the skin vary according to the skin thickness, which is different in different areas of the body, age, and sex. There are less collagen, elastin and ground substance of the dermis in thinner skin. ${ }^{2}$

Skin retraction involves several factors. For instance, the patient age has an influence, since skin loses its elasticity with advancing age. standard suctionassisted lipectomy (SAL) and ultrasound-assisted liposuction (UAL) is favored over excisional techniques, with the advantage of less and smaller scars. $^{3}$

Skin excision by "Benelli type", "inverted T" and lateral wedge resections may correct the body contour deformity but they might add more distress and embarrassment to the patients because of the residual scars or the nipple deformities. ${ }^{4}$ those patients with insufficient (bad) skin elasticity are the real candidates of skin reduction techniques which should be reserved only for them because of the associated less optimal cosmetic results. ${ }^{3}$

Combined liposuction and glandular liposculpturing was both reliable and safe. Great satisfaction has been shown by the patients. Also, the observers revealed acceptance to the cosmetic outcome. It 
could be an alternative reliable technique to the more expensive methods. ${ }^{5}$

The aim of our work is to evaluate skin redraping after traditional liposuction inmanagement of grade III gynecomastia Simon`sclassification.

\section{PATIENTS AND METHODS}

In our study, 20 patients who have grade III gynecomastia were selected with age group between 18 and 40 years old with mean $28.25 \pm 4.18,18$ patients were idiopathic while 2 patients were drug induced, 19 cases were bilateral and one case were unilateral. It was a prospective observational cohort study to assess the effectiveness traditional liposuction for correction of grade III gynecomastia with excision of the gland through a semicircular infraareolar incision when needed, 11 cases underwent surgical gland excision while 9 cases didn't need to. The study was conducted at Al-Azhar university hospitals (Al-Hussien and Sayed Galal).

Inclusion criteria: Age group from 18 to 40 years old with grade III gynecomastia Simon`s classification, patients whose weight is stable for at least 6 months, and BMI $>18 \&<32$.

Exclusion Criteria: Age group below18 or above 40 years old, patients with ongoing weight loss or post bariatric surgery patients, BMI 32, patient with connective tissue disorders or generalized mesenchymal weakness and autoimmune disease or any hindering comorbid diseases.

All the patients in the study were candidates for:

Preoperative:

Clinical assessment: Careful history taking and history of drugintake, generalcondition, local breast examination and genital examination, measurement of chest circumference, detection of the nipples positions regarding to chest cage, measuring sternum to nipples length and measuring skin fold by skinfold caliper.

Investigation: Routine preoperative investigations.

Intraoperative: In an upright position, the markings were performed the Patient was placed in supine position with arms abducted at 90degrees to administrate the General anesthesia.

Tumescent (500 cc of Normal Saline, $2 \mathrm{ml}$ of Epinephrine $1 / 250000,10 \mathrm{ml}$ of lidocaine $1 \%$, and $12.5 \mathrm{ml}$ of HCO3) is infiltrated in the breast by a $2 \mathrm{~mm}$ incision in anterior axillary line at the level of fourth intercostal space. After 15 minutes of injection, through the same incision, a blunt $4 \mathrm{~mm}$ Mercedes pattern liposuction cannula is inserted and connected to a graduated container. Suction of fat and breakdown of gland disk as well as septa was done with preserving of some fat in lower lateral pectoral area to create aesthetic male chest contour and avoid flat chest. An inferior infraareolar incision was made semi-circularly from which remnants of glandular tissue was removed closure of the wound in layers; subcutaneous layer by vicyl $2 / 0$ sutures and skin by vicryl $4 / 0$ sutures. No Drains were used in our cases. Closure of the suction wound by vicryl $4 / 0$ sutures. Dressing and compression garments were applied. After three days, the first dressing was done. Operation time was 30 to 90 minutes with the average 45 minutes. A compression garment is used for 3 months from the day of the operation and is being removed only for hygienic purposes and Sutures were removed two weeks postoperatively. There was no need for blood transfusion.

Objective assessment was done through detection of the nipples positions regarding to chest cage before the operation, one month and 3 months after. Measuring sternum to nipples length before the operation, one month and 3 months after. Measuring skin fold preoperative, immediately postoperative, one month and three months after the procedure by skinfold caliper.

Statistical analysis: we revised coded and tabulated the collected data and introduced it to a PC with Statistical package for Social Science (IBM Corp. Released 2011. IBM SPSS Statistics for Windows, Version 20.0. Armonk, NY: IBM Corp). According to the type of data gathered from each parameter, data was analyzed. Descriptive statistics: Mean, Standard deviation $( \pm$ SD) and range for parametric numerical data. Frequency and percentage of nonnumerical data. Analytical statistics: to assess the statistical significance of the difference between more than two study group means, Kruksall Wallis test or called one way ANOVA test was used. P value $<0.05$ was considered significant.

\section{RESULTS}

The mean of the age was $28.25 \pm 4.18$ as age ranged from 18 to 40 (Table 1 ).

\begin{tabular}{|c|c|}
\hline Age & No. $=\mathbf{2 0}$ \\
\hline Mean \pm SD & $28.25 \pm 4.18$ \\
\hline Range & $18-40$ \\
\hline
\end{tabular}

Table 1: Patients' demographic data.

\section{A. Subjective evaluation:}

\section{*Patient satisfaction assessment.}

Four patients scored very satisfied, eight stated satisfied, four stated neither satisfied nor dissatisfied while three patients declared dissatisfaction and only one was very dissatisfied. 
patient satisfaction assessment

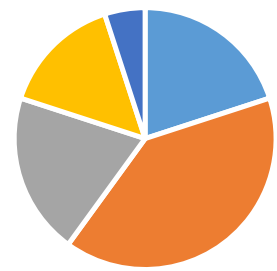

very satisfied

satisfied

neither satisfied nor dissatisfied

dissatisfied

Counting the scores, it is concluded that the treatment has been successful from aesthetic point and so in pectoral region anatomical reshaping of by percentage of $71 \%$ as follows;

4 patients scored the result as "very satisfied" $($ score 5$)=20$

8 patients as "satisfied" ( score 4$)=32$

4 as "neither satisfied nor dissatisfied"(score 3$)=12$

3 as "dissatisfied" (score 2$)=6$

1 as "very dissatisfied" (score 1$)=1$

\section{*surgeon satisfaction assessment}

After 3 months, The number of cases that were scored as; very satisfied were 6 , satisfied were 7 , neither satisfied nor satisfied were 4, dissatisfied were 2 and very dissatisfied was just one case

\section{surgeon satisfaction assessment}

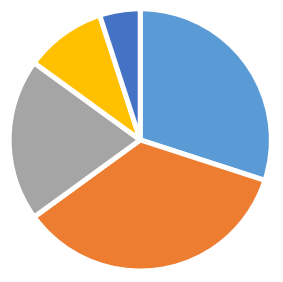

$$
\begin{aligned}
& \text { - very satisfied } \\
& \text { natisfied } \\
& \text { neither satisfied nor dissatisfied } \\
& \text { - dissatisfied } \\
& \text { - very dissatisfied }
\end{aligned}
$$

Counting the scores, the results were accepted by percentage of $75 \%$ as follows;

Very satisfied (score5) x 6 cases $=30$

Satisfied (score 4$) \times 7$ cases $=28$

Neither satisfied nor dissatisfied(score3) x $4=12$

Dissatisfied (score2) x 2 cases $=4$

Very dissatisfied (score1) $\mathrm{x} 1$ cases $=1$ patients and surgeon satisfaction

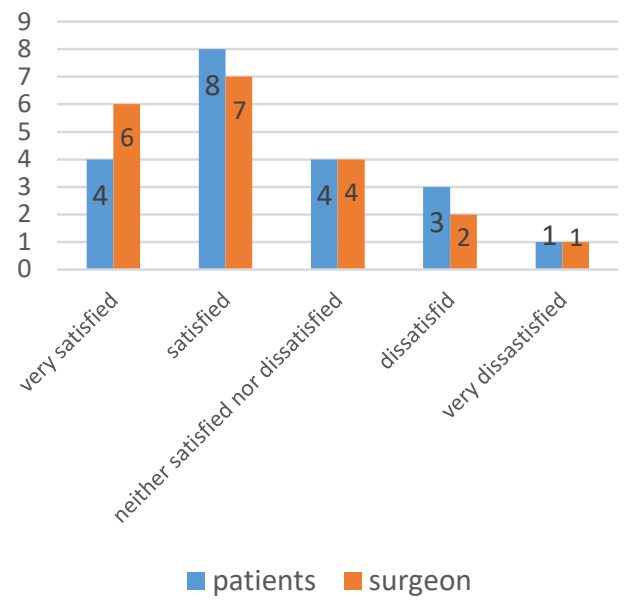

\section{B. Objective evaluation}

*Nipple position before, one and three months

\begin{tabular}{|c|c|c|c|c|c|c|}
\hline \multirow{3}{*}{$\begin{array}{l}\text { Patient } \\
\text { number }\end{array}$} & \multicolumn{6}{|c|}{ Nipple position } \\
\hline & \multicolumn{2}{|c|}{ preoperative } & \multicolumn{2}{|c|}{$\begin{array}{c}1 \text { month } \\
\text { postoperative }\end{array}$} & \multicolumn{2}{|c|}{$\begin{array}{c}3 \text { months } \\
\text { postoperative }\end{array}$} \\
\hline & $\begin{array}{l}\text { Right } \\
\text { side }\end{array}$ & $\begin{array}{l}\text { Left } \\
\text { side }\end{array}$ & $\begin{array}{r}\text { Right } \\
\text { side }\end{array}$ & $\begin{array}{l}\text { Left } \\
\text { side }\end{array}$ & $\begin{array}{l}\text { Right } \\
\text { side }\end{array}$ & $\begin{array}{l}\text { Left } \\
\text { side }\end{array}$ \\
\hline 1 & $8^{\text {th }}$ & $8^{\text {th }}$ & $7^{\text {th }}$ & 7th & $6^{\text {th }}$ & $5^{\text {th }}$ \\
\hline 2 & $8^{\text {th }}$ & $8^{\text {th }}$ & $7^{\text {th }}$ & $7^{\text {th }}$ & $6^{\text {th }}$ & $6^{\text {th }}$ \\
\hline 3 & $8^{\text {th }}$ & $8^{\text {th }}$ & $7^{\text {th }}$ & $7^{\text {th }}$ & $7^{\text {th }}$ & $7^{\text {th }}$ \\
\hline 4 & $6^{\text {th }}$ & $6^{\text {th }}$ & $5^{\text {th }}$ & $5^{\text {th }}$ & $5^{\text {th }}$ & $4^{\text {th }}$ \\
\hline 5 & $9^{\text {th }}$ & $8^{\text {th }}$ & $8^{\text {th }}$ & $7^{\text {th }}$ & $7^{\text {th }}$ & $6^{\text {th }}$ \\
\hline 6 & $7^{\text {th }}$ & $8^{\text {th }}$ & $7^{\text {th }}$ & $7^{\text {th }}$ & $6^{\text {th }}$ & $7^{\text {th }}$ \\
\hline 7 & $6^{\text {th }}$ & $6^{\text {th }}$ & $5^{\text {th }}$ & $5^{\text {th }}$ & $5^{\text {th }}$ & $4^{\text {th }}$ \\
\hline 8 & $7^{\text {th }}$ & $7^{\text {th }}$ & $6^{\text {th }}$ & $6^{\text {th }}$ & $6^{\text {th }}$ & $5^{\text {th }}$ \\
\hline 9 & $6^{\text {th }}$ & $6^{\text {th }}$ & $4^{\text {th }}$ & $4^{\text {th }}$ & $4^{\text {th }}$ & $4^{\text {th }}$ \\
\hline 10 & $7^{\text {th }}$ & $7^{\text {th }}$ & $6^{\text {th }}$ & $6^{\text {th }}$ & $5^{\text {th }}$ & $5^{\text {th }}$ \\
\hline 11 & $7^{\text {th }}$ & $6^{\text {th }}$ & $7^{\text {th }}$ & $6^{\text {th }}$ & $6^{\text {th }}$ & $5^{\text {th }}$ \\
\hline 12 & $9^{\text {th }}$ & $8^{\text {th }}$ & $8^{\text {th }}$ & $7^{\text {th }}$ & $7^{\text {th }}$ & $6^{\text {th }}$ \\
\hline 13 & $7^{\text {th }}$ & $6^{\text {th }}$ & $6^{\text {th }}$ & $6^{\text {th }}$ & $5^{\text {th }}$ & $5^{\text {th }}$ \\
\hline 14 & $8^{\text {th }}$ & $8^{\text {th }}$ & $7^{\text {th }}$ & $7^{\text {th }}$ & $6^{\text {th }}$ & $5^{\text {th }}$ \\
\hline 15 & $6^{\text {th }}$ & $6^{\text {th }}$ & $5^{\text {th }}$ & $6^{\text {th }}$ & $4^{\text {th }}$ & $5^{\text {th }}$ \\
\hline 16 & $6^{\text {th }}$ & $6^{\text {th }}$ & $5^{\text {th }}$ & $6^{\text {th }}$ & $5^{\text {th }}$ & $5^{\text {th }}$ \\
\hline 17 & $7^{\text {th }}$ & $7^{\text {th }}$ & $6^{\text {th }}$ & $6^{\text {th }}$ & $5^{\text {th }}$ & $5^{\text {th }}$ \\
\hline 18 & $8^{\text {th }}$ & $5^{\text {th }}$ & $6^{\text {th }}$ & $5^{\text {th }}$ & $5^{\text {th }}$ & $5^{\text {th }}$ \\
\hline 19 & $7^{\text {th }}$ & $6^{\text {th }}$ & $6^{\text {th }}$ & $6^{\text {th }}$ & $5^{\text {th }}$ & $5^{\text {th }}$ \\
\hline 20 & $8^{\text {th }}$ & $8^{\text {th }}$ & $7^{\text {th }}$ & $7^{\text {th }}$ & $6^{\text {th }}$ & 7th \\
\hline
\end{tabular}
after the surgery

Mean nipple positionpreoperatively, one month and three months postoperative were respectively at 8th, 7th and 5th(Table 2).

Table 2: Nipples position before, one and three months after the surgery 


\section{*Sternal notch to nipple length}

The average sternal notch to nipple length pre and three months postoperative were respectively $27 \mathrm{cmand} 22 \mathrm{~cm}$ (Table 3).

\begin{tabular}{|c|c|c|c|c|c|c|}
\hline \multirow{3}{*}{$\begin{array}{l}\text { Patient } \\
\text { number }\end{array}$} & \multicolumn{6}{|c|}{ Sternal notch to nipple length } \\
\hline & \multicolumn{2}{|c|}{ preoperative } & \multicolumn{2}{|c|}{$\begin{array}{c}1 \text { month } \\
\text { postoperative }\end{array}$} & \multicolumn{2}{|c|}{$\begin{array}{c}3 \text { months } \\
\text { postoperative }\end{array}$} \\
\hline & $\begin{array}{l}\text { Right } \\
\text { side }\end{array}$ & $\begin{array}{l}\text { Left } \\
\text { side }\end{array}$ & $\begin{array}{r}\text { Right } \\
\text { side }\end{array}$ & $\begin{array}{l}\text { Left } \\
\text { side }\end{array}$ & $\begin{array}{l}\text { Right } \\
\text { side }\end{array}$ & $\begin{array}{l}\text { Left } \\
\text { side }\end{array}$ \\
\hline 1 & 28 & 27 & 27 & 26 & 25 & 24 \\
\hline 2 & 28 & 28 & 27 & 27 & 24 & 24 \\
\hline 3 & 27 & 28 & 26 & 27 & 25 & 25 \\
\hline 4 & 23 & 23 & 22 & 21 & 21 & 20 \\
\hline 5 & 30 & 28 & 27 & 26 & 25 & 24 \\
\hline 6 & 26 & 27 & 26 & 26 & 23 & 24 \\
\hline 7 & 25 & 25 & 23 & 23 & 22 & 20 \\
\hline 8 & 26 & 27 & 24 & 24 & 21 & 22 \\
\hline 9 & 24 & 25 & 22 & 23 & 21 & 22 \\
\hline 10 & 27 & 26 & 25 & 25 & 23 & 22 \\
\hline 11 & 26 & 25 & 24 & 23 & 22 & 21 \\
\hline 12 & 30 & 29 & 27 & 27 & 25 & 24 \\
\hline 13 & 26 & 25 & 24 & 24 & 23 & 21 \\
\hline 14 & 29 & 27 & 27 & 26 & 25 & 23 \\
\hline 15 & 23 & 23 & 21 & 22 & 20 & 21 \\
\hline 16 & 26 & 26 & 23 & 24 & 22 & 23 \\
\hline 17 & 28 & 28 & 25 & 25 & 23 & 22 \\
\hline 18 & 28 & 22 & 25 & 22 & 23 & 22 \\
\hline 19 & 28 & 25 & 26 & 24 & 23 & 22 \\
\hline 20 & 29 & 30 & 26 & 27 & 24 & 24 \\
\hline
\end{tabular}

Table 3: Sternal notch to nipple length

\section{Postoperative results:}

According to postoperative complications; it was found that two out of twenty patients have shown persistent non redraped skin laxity that needed skin excision afterwards, and also two cases developed skin ecchymosis (10\%) that resolved within two weeks before the first visit. All the cases were hematoma, seroma and infection free $(100 \%)$. Only one case had developed nipple retraction (10\%) and another one developed contour irregularity (5\%) (Table 6).

\begin{tabular}{|l|c|l|}
\hline \multicolumn{1}{|c|}{ Complication } & $\begin{array}{c}\text { Number of } \\
\text { cases }\end{array}$ & Percent \\
\hline Skin laxity & 2 & $10.0 \%$ \\
\hline Skin ecchymosis & 2 & $10.0 \%$ \\
\hline Nipple retraction & 1 & $5.0 \%$ \\
\hline Contour Irregularity & 1 & $5.0 \%$ \\
\hline Hematoma & 0 & $0.0 \%$ \\
\hline Seroma & 0 & $0.0 \%$ \\
\hline Infection & 0 & $0.0 \%$ \\
\hline
\end{tabular}

Table (4): Complications occurred in 20 patients.
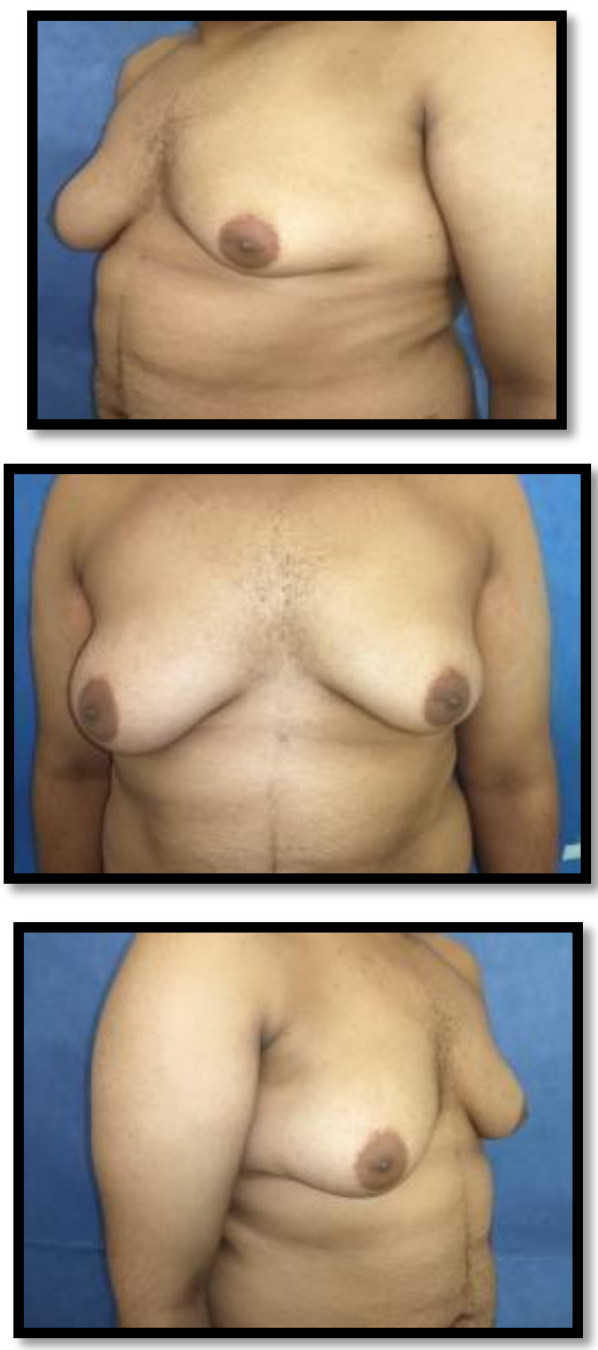

Fig. 1: A,B,C: preoperatively
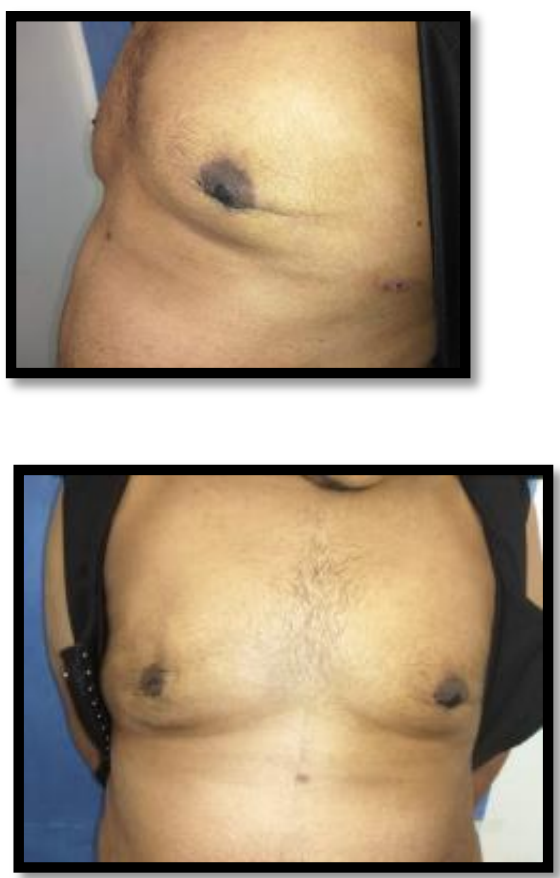


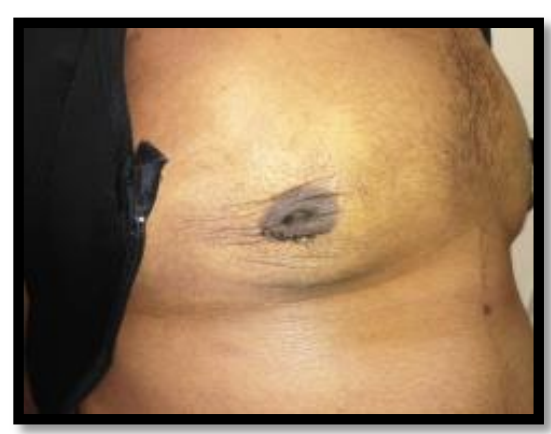

Fig. 1: D,E,F: posteperatively
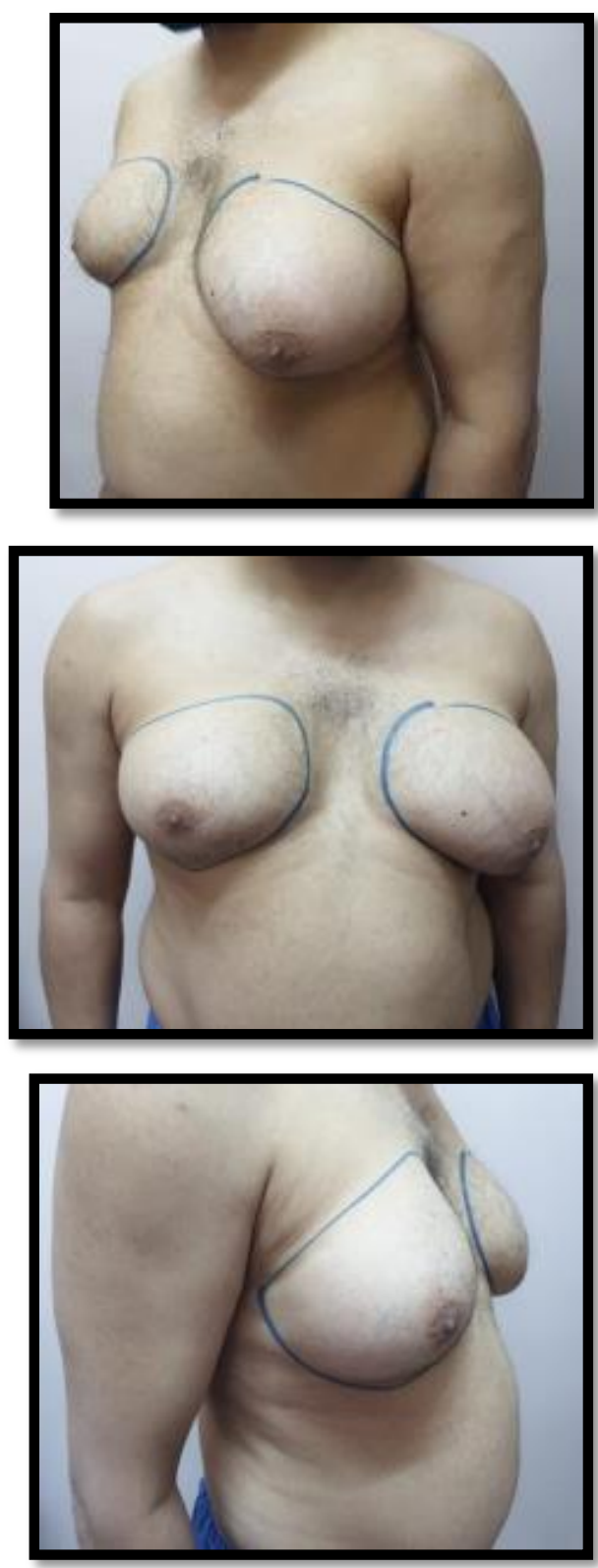

Fig. 2: A,B,C: preoperatively
Plastic Surgery and Burn
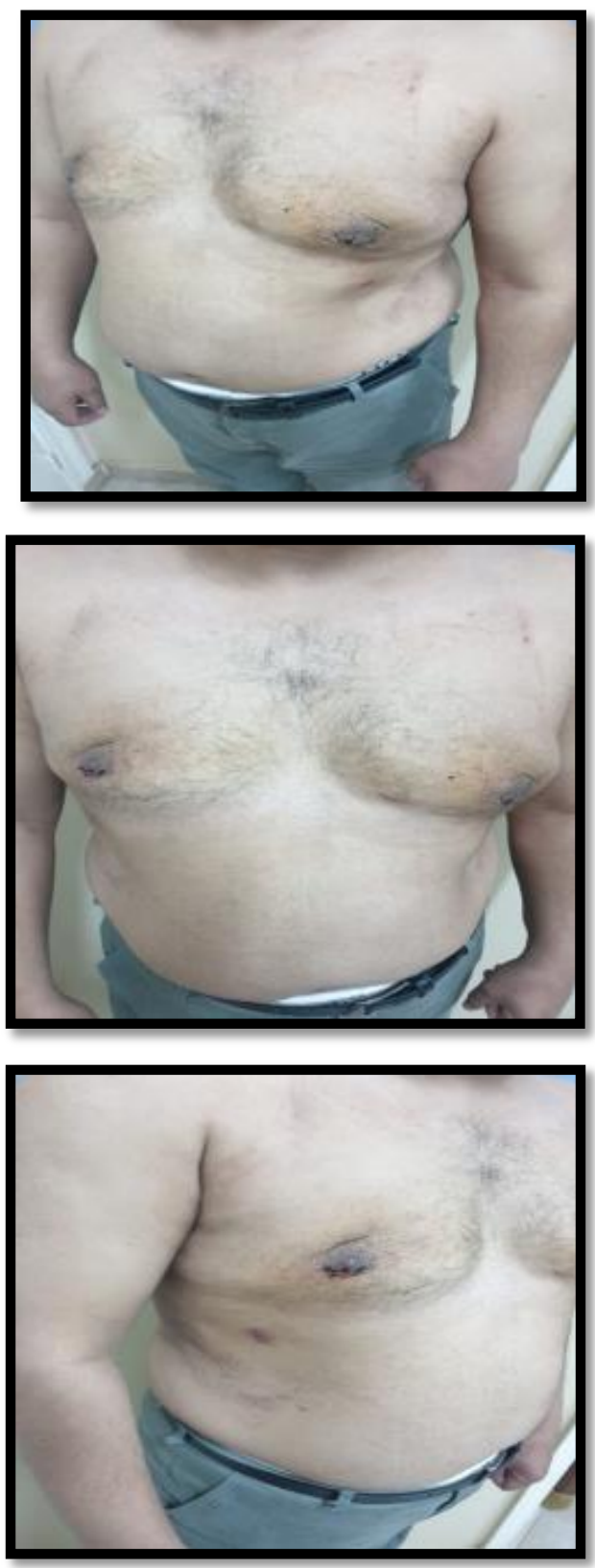

Fig. 2: D,E,F: postoperatively 

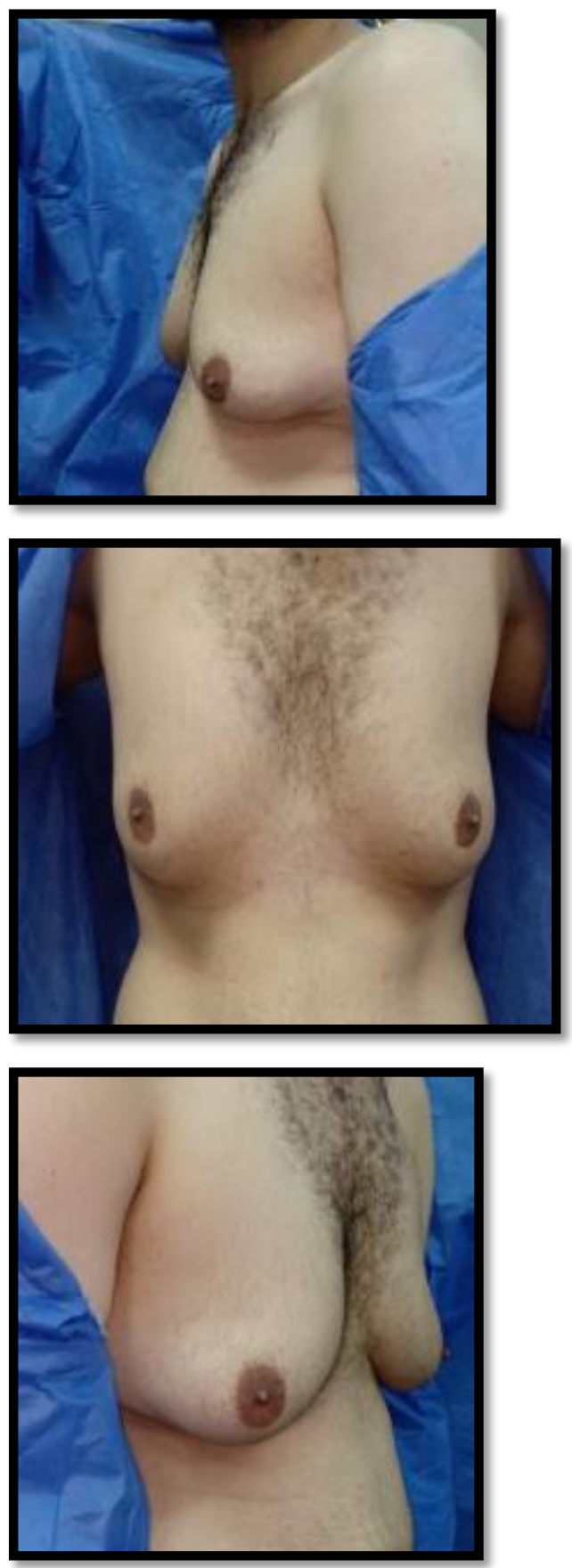

Fig. 3: A,B,C: preoperatively
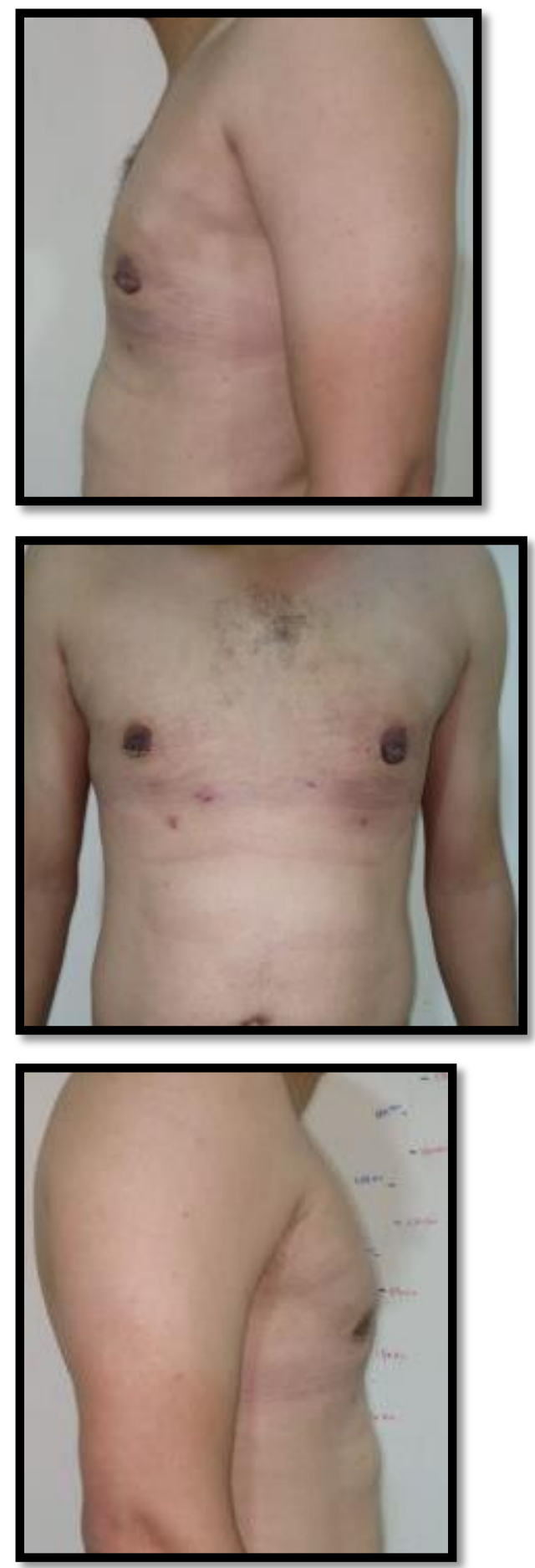

Fig. 3: D,E,F: postoperatively

\section{DISCUSSION}

Surgical correction of 'gynecomastiai is known to be the golden standard therapy, however it is still challenging to select the optimum surgical. The common goal is to achieve an aesthetic male chest wall with minimum scars. despite the wide range of surgical techniques, surgeons still face difficulties in choosing the suitable technique for each patient as there is no single technique is suitable for all forms of 'gynecomastia`. ${ }^{\prime}$ The techniques of breast surgery 
appear to be the most important factor to achieve good cosmesis, so that the non-scaring methods are preferred. $^{7}$

Gasparotti M stated in a study that liposuction by aspiration of the superficial areolar layer of fat allows us to obtain a very thin cutaneous adipose flap with good retractability and such a thin cutaneous adipose flap -subsequently supported by an antigravitational elastic and compressive bandage- will permit controlled iatrogenic skin retraction. ${ }^{13}$

We found in our study that appropriate liposuction followed by wearing the compressive corset for at least tree months after the procedures leads to satisfying skin redraping in young patient with good skin quality.

A study that was held by Abdelrahman and Steinvall ${ }^{5}$ testing patient satisfaction and surgeon satisfaction on using liposculpture as a Single treatment option for grades I and II 'gynaecomastia', reported that $92 \%$ of patient and observer surgeons revealed "very satisfied" or "satisfied" and concluded that with the use of the fat disruptor cannula, the combined liposuction and glandular liposculpturing was a safe and reliable technique as patients shew great satisfaction, as well as the observer surgeons. It may be used as an alternative method in low-income countries such as Egypt to the more expensive and risky methods such as laser assisted liposuction and.

Using the same evaluation scale, our study assessed satisfaction of twenty patients but with grade III gynecomastia and it was satisfying for most of the patients except only two cases who needed second session of skin excision.

In Ashour et al. ${ }^{8}, 143$ patients (none of them was grade III) were treated by Liposuction excision of Gynecomastia by liposuction opening technique through the period from March 2010 to March 2014. Liposuction and surgical excision were done from the same stab of the liposuction at midaxillary line in the 5th or the 6th intercostal space, Traditional Liposuction is done first then the glandular disc was released from its deep attachment and from subcutaneous and nipple attachment by scissors. This studyreported; "The axillary liposuction excision technique was safe and associated with good esthetic results. The technique is suitable for those who stress to appear unoperated".

We followed the similar principle of treating gynecomastia by only traditional liposuction without skin excision, but our sample contains grade III cases only.

Yordanov et al. ${ }^{9}$ used traditional liposuction with inferior periareolar incision from excision of gynecomastia in 11 patients. There were 10 uncomplicated procedures and only one patient developed postoperative unilateral seroma $(0.1 \%)$ which resolved with aspiration andcompression.
In this study we tried to evaluate skin redraping after liposuction combined with surgical excision of the gland -if needed- through semicircular periareolar incision of grade III gynecomastia. The study was held on twenty patients with average age 25.25.

On postoperative assessment, Patients showed great satisfaction about their final appearance; only two patients had postoperative skin ecchymosis that resolved within two weeks, that contributes to $10 \%$ of the cases. another two patients $10 \%$ have shown persistent non redraped skin laxity that needed skin excision afterwards. One patient had nipple retraction due to excess glandular tissue excision that contributes $5 \%$ of the cases and also one patient suffered from contour irregularity due to asymmetric liposuction which forms $5 \%$ of the cases. No patient showed hematoma, seroma, nipple necrosis or infection. The results were shown to be more reliable in comparison to the other methods published in research series despite the lack of a control group, and the small number of procedures.

Carrie et al. ${ }^{10}$ treated 60 Cases by surgical excision through semicircular incision without Liposuction, higherrateofcomplicationsappearedincludinghemato ma $(16.1 \%)$, seroma $(9.4 \%)$ and Nipple retraction due to over resection (18.7\%).

Lista and Ahmad ${ }^{11}$ treated 99 patients with power assisted Liposuction. Residual solid masses were noticed in three patients $(3 \%)$ which were found to be Fibroglandular breast tissues deep to the nipple/areolar complex and a complementary excisional technique was needed later, moreover two patients (2\%) suffered from seroma. No other complications were documented.

Longheu et al. ${ }^{12}$ underwent surgical treatment of gynecomastia between September 2008 and January 2015, 50 patients were included in this study. Webster Technique with periareolar incision was performed on 28 patients $(56 \%)$, Pitanguy Technique with transareolar incision in 2 patients (4\%), Davidson concentric circles technique was performed in 16 patients (32\%), In 4 patients $(8 \%)$ a mixture surgical technique wasperformed (Websterand Davidsonmethods). Webster Technique, Pitanguary technique and mixed technique show neither early nor late complications while in Davidson technique 2patients developedhematoma.

Several factors are found to explain our overall success rate; The selection of young nonsmoker patient with no co morbid diseases or evidence of defective elasticity (varicosities or hernias), the adequate preparation, amount and duration of the tumescent and the proper choice of the corset size and fiber as well as wearing it for the whole time of the study (3 months).

The procedure is considered rewarding for both the surgeon and the patient as the recovery time has decreased and patients resumed their activities earlier. Surgical excision by semicircular periareolar incision also adds other advantages to the maneuver 
as the periareolar incision make the scar not well defined as it become camouflaged by the color change between normal skin and the areola. The two unpleasant cases $10 \%$ who presented with persistent skin laxity that needed second session of skin excision, were both above 30 years old and have a bad skin quality (redundant abdominal and arm skin).

Further studies are needed to detect the factors that determine the recoil quality of the skin for better case selection and avoidance of post-operative redundancy.

\section{CONCLUSION}

Conventional liposuction alone could be a reliable method to treat grade III gynecomastia in young patient with a good skin quality and helps in avoidance of undesirable scars.

\section{REFERENCES}

1. Cuhaci N. Gynecomastia: Clinical evaluation and management. Indian J Endocrinol Metab. 2014; 18 (2): $150-58$.

2. Hussain SH, Limthongkul B and Humphreys TR. The Biomechanical Properties of the Skin. Dermatologic Surgery, 2013; 39(2): 193-203.

3. Fruhstorfer BH and Malata CM. A systematic approach to the surgical treatment of gynaecomastia. Br J Plast Surg., 2013; 56 (3): $237 \mathrm{e} 46$.

4. Wiesman IM, Lehman JA, Parker MG, et al. Gynecomastia: an outcome analysis. Ann Plast Surg., 2010; 53(2):97-101.
5. Abdelrahman I, Steinvall I, Mossaad B, et al. Evaluation of Glandular Liposculpture as a Single Treatment for Grades I and II Gynaecomastia. AesthPlast Surg., 2018; 42: 1222-30.

6. Carlos AM, Scott MR and Sean GB. The Nipple-Areola Preserving Mastectomy: The Value of Adding a Delay Procedure. PlastReconstr Surg Glob Open, 2016; 4(11): 1098-106.

7. Irvin MW, James AL, Michael GP, et al. Gynecomastia:An Outcome Analysis, Annals of Plastic Surgery, 2010; 53(2): 97-101.

8. Ashour HS. Liposuction excision of gynecomastia through an axillary liposuction opening. The Egyptian Journal of Surgery, 2015; 15: 170-6.

9. Yordanov Y, Lasso JM and Shef A. Combined Surgical Treatment of Gynecomastia. De Gruyter Open Acta medica Bulgarica., 2015; 11: 43-8.

10. Carrie AL, Carissa LG, Daniel JO, et al. Treatment of adolescent gynecomastia. Journal of Pediatric Surgery, 2010; 45:650-4.

11. Lista F and Ahmad J. Power-assisted liposuction and the pullthrough technique for the treatment of gynecomastia, PlastReconstr Surg., 2011; 121(3):740- 7.

12. Longheu A, Medas F and Corrias F. Surgical management of gynecomastia: experience of a general surgery center. G Chir., 2016; 6: 150-4.

13. Gasparotti M. Superficial liposuction: a new application of the technique for aged and flaccid skin. Aesthetic Plast Surg. 1992 Spring; 16 (2): 141-53.

doi: 10.1007/BF00450606. PMID: 1570777. 